\title{
Filosofía del límite o pensar en el vértigo
}

\author{
Blanca Solares
}

$\mathrm{E}$

1 derrumbamiento del socialismo soviético, la guerra de los Balcanes, el obstinado resurgir de los fundamentalismos religiosos y las ideologías xenofóbicas, la creciente reificación de la inteligencia a través de los mass media, para no hablar del crónico sismógrafo de la miseria que atenaza a dos terceras partes del planeta, en la actualidad, parecen corresponderse con el desmoronamiento de-constructivista y el vano intento de una restauración ilustrada que acorralan en las últimas décadas al discurso filosófico.

El paradigma de la comunicación forjado en Alemania por J. Habermas y sus buenos deseos de una "comunidad de comunicación ideal", a manera de correctivo de una razón plenamente instrumentalizada -que, por contraste, no viene sino a poner de relieve la fuerza del diagnóstico "negativo" de los viejos maestros frankfurteanos, T. W. Adorno y M. Horkheimer-, de una parte; y, de otra, el amplio espectro posmodernista de un "pensiero débole" empeñado en la disolución de la razón ilustrada a través de una ensayística aleatoria e irónicamente complementaria a la estrategia global, constituyen el doble fuego cerrado en medio del cual a la filosofía, una vez fracasados sus "metarrelatos", sólo le quedaría completar, de modo penoso o con decoro, la autoaniquilación proclamada por sus enterradores, al lado de la agonía del arte y de la historia.

Es en ese rápido y crudo trazado de la situación filosófica que, en los últimos años, ha comenzado a hacerse presente de manera insistente el nombre de uno de los filósofos más peculiares en el ámbito de la filosofía hispana de este cambio de siglo, Eugenio Trías, autor de más de una veintena de libros, ganador del Premio Anagrama de Ensayo por su obra El artista y la ciudad (1976), del Premio Nacional de Ensayo, en 1982, por su libro Lo bello y lo siniestro y, en 1992, del Premio Internacional Friedrich Nietzsche, en Italia, por el conjunto de su obra, premio concedido, antes también, a K. Popper, R. Rorty, E. Severino y J. Derrida. 
Es con relación a uno de los temas más complejos dejados pendientes por la teoría crítica, la dimensión religiosa del ser humano estrechamente vinculada con la filosofía, la estética y el símbolo que se abrió mi interés por $L a$ edad del espíritu, libro que -junto con el Tratado de la pasión (1979)-, es quizá la obra más conocida de Eugenio Trías y que no sólo agotó su primera edición en un mes, sino que está a punto de agotar la tercera y anuncia ya la cuarta. ${ }^{1}$ Difícilmente puede uno salir del primero de los libros de La edad del espíritu, pues en realidad son tres, sin sufrir una especie de vuelco en nuestra concepción de la historia humana y su futuro posible, mejor si se hace, como lector consecuente, la lectura de toda la obra. Sin embargo, no es un análisis de este libro lo que me propongo en estas líneas, sino intentar explicar por qué, desde mi punto de vista, el pensamiento de Eugenio Trías constituye una de las visiones del mundo más consistentes e importantes de este cambio de milenio, en la medida en que no sólo retoma la herencia del "pensar negativo" contemporáneo y rebasa con creces tanto la teoría de la acción comunicativa como la "disolvencia posmodernista", sino en que logra una verdadera recreación del discurso filosófico clásico y una renovación del pensamiento filosófico moderno.

De esta capacidad de recrear incluso su propio discurso, se podrá ser testigo, si se tiene la suerte de poder asistir a los seminarios del autor. Y es que Eugenio Trías no es un académico, ni un erudito profesor que llega a exponer su pensamiento y termina con brillantez la sesión, sino un auténtico filósofo, es decir, alguien que asume la aventura de pensar como riesgo y el compromiso para con ella como destino. Si los sofistas, esos pensadores que exponían sus ideas en el seno de la polis, enseñando a reflexionar, sabían que la filosofía era enseñanza, paideia, pedagogía, para la que era necesario contar con un maestro, Eugenio Trías asume este lugar, hoy atípico, sin remordimientos ni inseguridades de ningún tipo, con la plena conciencia de que el pensar se juega tanto en la exposición como en la asunción de ese difícil rol de suscitar, provocar y guiar a otros en el camino del conocimiento con el único fin de que cada uno pueda realizar su experiencia propia. Es esa atmósfera fascinante y de alta tensión, la que se respira en sus seminarios, tanto como el aire que anima su presencia. ${ }^{2}$

${ }^{1}$ En 1995, publiqué un homenaje póstumo a Dialéctica del iluminismo, de Adorno y Horkheimer, Tu cabello de oro Margarethe. Fragmentos sobre odio, resistencia y modernidad (Porrúa). Destaco la importancia fundamental de este análisis de la modernidad pero marco también lo que entiendo por "aporías" del pensamiento crítico, respecto de las cuales la reflexión sobre la dimensión simbólica de la cultura de Trías, me parece, abre un horizonte radical.

2 El presente trabajo intenta una síntesis escueta del complejo "sistema" de pensamiento de la filosofía del límite, elaborado a lo largo de más de veinte años por $\mathrm{E}$. 
Si hubo un momento en el que el discurso filosófico parecía agotado, la filosofía del límite de Eugenio Trías abre, por contraste, un vasto horizonte y nos muestra, sobre todo, que para acceder al reto de la episteme, a esa "ciencia que se busca" desde el origen griego de la filosofía, será necesario una autotrasformación, hacerse de una actitud menos cerrada a lo desconocido, lo inconmensurable, el fundamento de todo cuanto existe, eso que somos y que nos constituye, llámesele a priori, absoluto o Dios, como en las tradiciones religiosas de las que la filosofía moderna se esfuerza en separarse, descartándolas como mera evasión metafísica, para abrirse, a esa terra ignota y acceder a la dimensión trágica de la existencia. No se pretende, pues, construir una nueva episteme que restaure el primado de una "ciencia filosófica" sobre todo saber y hacer, ni mucho menos de aceptar que sea la ciencia moderna fundada en la técnica, la que ocupe ese lugar, sino de cobrar conciencia, en el hacer filosófico y reflexivo de la propia experiencia de que en el logos, pensar-decir, como Trías lo define, se cifra la dimensión trágica de un conocimiento enroscado en la aporía y la paradoja radical del "ser del límite" como limite.

Cabe así comenzar nuevamente por el principio. Contestar de nueva cuenta a la pregunta y "¿qué es la filosofía?” Con relación a su contenido temático no hay consenso. Sobre todo en nuestro siglo, son numerosas las objeciones críticas en contra del modo tradicional de entender a la filosofía, en tanto reflexión de "el ser como ser" o el conocimiento de "el ser mismo" -autó tó ón, desde Parménides y Aristóteles-, en nombre del miedo a recaer en la metafísica y la tarea de acabar con todo intento de trascendencia, en la que parece sumida la modernidad en marcha. Esta postura es, sobre todo, un rasgo tanto de la filosofía analítica como de la filosofía dialéctica y el materialismo dominantes en nuestros círculos académicos. No obstante, la filosofía tampoco puede desprenderse tan fácilmente de la misma pretensión que le da vida, la de comprender lo que puede entenderse por existencia, su vocación de arribar a un horizonte de sentido radical donde se deciden las cuestiones que se suscitan en los fundamentos mismos de todo conocimiento y todo lenguaje y que no pueden sino llamarse ontológicas.

La "filosofía del límite" configura en nuestro contexto una inauguratio, funda una nueva manera de comprender al ser, una nueva forma de entender eso que llamamos hombre. Y no se trata de que los elementos que configuran la noción del ser que la filosofía del límite plantea no hayan sido nunca antes expuestos, sino de que en filosofía, como dice E. Trías, toda innovación, en

Trías. Esta síntesis fue discutida por el autor en los seminarios privados y académicos realizados a lo largo del 2000-2001 en la Universidad Pompeu Fabra, Barcelona, mismos a los que tuve la suerte de asistir regularmente. 
realidad, consiste en un desplazamiento del centro de gravedad de los conceptos principales hacia otros márgenes, a fin de que pueda aflorar una nueva organización de la conciencia reflexiva, un nuevo cosmos del pensar-decir acerca del ser que, por una u otra razón problemática, no articulaba de manera central la comprensión filosófica. Lo propio de la actividad filosófica consiste tanto en promover un desplazamiento de esta índole, como en cobrar conciencia de que en ese pulso o flexión que se ejerce sobre la trama de las ideas se abate su solidificación. En ello radica toda pretensión de innovación que conlleva de suyo, aquí, el hacerse cargo de la tradición discursiva de la filosofía y conducirla hasta el límite de una nueva proposición.

Hay, sin embargo, otros dos puntos con los que una filosofía con tales pretensiones debe también entrar en relación, en primera instancia con el dato inaugural que abre la reflexión, dato o punto de partida que guía el itinerario filosófico y, en segundo, con la elaboración de un trazado de determinaciones conceptuales o categorías propias.

En ese punto de partida, la proposición filosófica de E. Trías es propiamente la dimensión ontológica de límite que encuentra su raíz, dice él, por un lado, en el asombro interrogante que le produce la inteligencia de la propia existencia, en todas sus formas de manifestarse, lingüísticas, poéticas, simbólicas, prácticas; y, por otro, la categoría de libertad. Ambas nociones, inteligencia y libertad, interrelacionadas y que competen específicamente a la filosofía, en la medida en que la ciencia se ha ocupado de cuestiones como "el origen del universo" o el desarrollo de la investigación biogenética, pero no del proceso mismo del devenir del don de la existencia en pasión-inteligente, a la vez que tampoco de esa peculiaridad de ser imprevisible de la condición humana en el fundamento de la libertad, pues, lo específico del hombre es no estar determinado por ningún tipo de "causa-efecto", sino por la apertura entre uno y otro de un hiato limítrofe que provoca un principio de indeterminación, incluso más radical que el de la física. ${ }^{3}$

3 Con relación a la fundación de una ontología del límite y las nociones de asombro, inteligencia y libertad remito al lector a dos de los primeros libros de Eugenio Trías, La aventura filosófica. Madrid, Mondadori, 1988 y Tratado de la pasión. Madrid, Taurus, 1979, que parecen trazar ya desde hace tiempo las líneas fundamentales de un pensamiento que aparece maduro en su tetralogía fundamental: Lógica del límite. Barcelona, Destino, 1991; La edad del espíritu. Barcelona, Destino, 1994; La razón fronteriza. Barcelona, Destino, 1999 y Ética y condición humana. Barcelona, Península, 2000. 


\section{Filosofía: logos y poíesis}

Siempre que se tome, con la intención de una lectura seria, alguno de los libros de E. Trías, sorprenderá la elegancia y la claridad con la que puede exponer los conceptos más complejos. Se echa una vez más por tierra (recuérdese ya a Ortega y Gasset y a María Zambrano) el obtuso tabú de impermeabilidad idiomática del castellano al pensar filosófico, en contraste con el alemán. Pero, si se accede al conjunto de su obra sorprenderá, sobre todo, la perseverancia con la que pacientemente va conectando el desarrollo de un tema filosófico con otro hasta llegar a conformar lo que va apareciendo a lo largo de sus textos como un sistema filosófico contundente. Mucho se ha intentado desacreditar el propósito de "sistema" filosófico. No obstante, el autor se mantiene firme frente a lo que para él es innegociable: "la turgencia del concepto, la formalización arquitectónica y la estructuración de un orden, todo lo oxigenado que se quiera, pero que es lo específico de la filosofía".

En realidad, la filosofía, para E. Trías, es el desarrollo de una pasión, llevada hasta sus últimas consecuencias. Filos: amor; sofía: conocimiento. La filosofía o el "amor al saber", para él, es su forma argumenta, de modo tal que la elaboración sistemática de conceptos coincide con el trayecto en profundidad de La aventura filosófica exponiéndose como una investigación que es esencialmente escritura, una forja con y en la textura del lenguaje, la materia del pensar. Es la escritura el lugar donde el autor da también forma a sus dos más íntimas vocaciones, la poesía y la música. Pues, el pensamiento, para E. Trías, no es nada sin su manifestación en la escritura y la palabra, espacios donde la filosofía encuentra como forma propia de presentarse su proyección poética, arquitectónica y musical.

Desde Platón, haciendo palpable la voz de Sócrates a través de la máscara de signos de sus Diálogos, la filosofía es sobre todo escritura, pues no basta el habla para la consumación del acto filosófico, dice Trías, sino que el filósofo ha de ser siempre -en palabras del poeta José Ángel Valente, recientemente fallecido, y que en más de un punto guarda afinidad con nuestro autor-, un escritor al que su vocación le exige, cuando es auténtica, una "relación carnal" con la escritura, la entrega, el cuidado y la disposición de lo que se produce. Pues el pensamiento al inscribirse no es un simple proceso espontáneo de expresión o el mero manipular de un utensilio, sino él mismo un quehacer abismático, un reto o una especie de retornante desafío creativo y poético. Y no es que el autor pretenda que filosofía, poesía y literatura pueden confundirse. Por el contrario, es el primero en oponerse a mezclas heterogéneas que liquiden las especificidades tan difíciles de ser alzadas, sino que, para él, la filosofía, desde su raíz, es creación, "incluso, uno de los más altos modos de creación” exigente y complejo. Aclara E. Trías: 
La poesía puede proveerse de argumentación filosófica para suscitar su despliegue de imágenes, ritmos y rimas. [...] Pero en filosofía la relación se invierte por necesidad; las imágenes, los sonidos, el repicar de la campana (que anuncia un tiempo anterior a nuestro tiempo de vida) todo ello constituye el material verbal sin el cual no puede levantar el vuelo la voz siempre plural, siempre compleja, en que una propuesta filosófica, unitaria y diversificada a la vez, llega a articularse y desarrollarse. ${ }^{4}$

Más allá del asalto posmoderno del toto revolutum entre poesía, literatura y conocimiento, la filosofía debe mostrar, según E. Trías, las diferencias y las distancias, entre unas y otras, para comprenderlas en su constelación precisa como despliegue del pensar-decir del hombre en el límite. En tanto que es escritura filosófica, como la poesía, se debe a un ajuste de cuentas con la musicalidad de la expresión, las medidas, los ritmos, el desarrollo de un tema, la recurrencia a imágenes para encarnar en la materialidad del texto. Pero lo propio de la filosofía es penetrar en la elaboración conceptual compleja, expresiva y específica de ella con relación a temas tan antinómicos y contradictorios como el hombre, el mundo, el misterio o el enigma de lo que somos y de nuestra propia condición.

Es en este sentido, en el que la escritura filosófica reconduce su propia especificidad en el seno del lenguaje, que puede entrar entonces en conjunción ontológica con las dimensiones arquitectónicas y musicales. De tal manera que, para E. Trías, el encuentro de Nietzsche con Wagner no es casual, sobre todo, si tomamos en cuenta que en filosofía de lo que se trata es de pensar musicalmente, elevando en su ejecución un tempo habitable de conjunción entre el ritmo de lo orgánico y la constructiva de lo cultural (tópico al que se aproxima el Lévi-Strauss de las Mythologiques) y del que quizá, después de todo, el mismo principio de variación de la música sea el que mejor refleje la condición humana, las metamorfosis del ser y, por lo tanto, las variaciones mismas que el pensamiento debe captar y reflexionar. La poíesis (el hacer aparecer o producir) filosófica se cumple si ésta se muestra y plasma en una materialidad que evoque esa forma musical del ser, si la textualidad filosófica evoca la música que acompaña a la vida, si logra hacernos participar del misterio que entraña lo indescifrable e imprevisible, pues si Dios es algo, es música, diría Nietzsche. ${ }^{5}$

${ }^{4}$ E. Trías, "Filosofía y poesía", en El Cultural, supl. de El Mundo. Madrid, 25 de octubre de 2000 , p. 3.

5 Véase E. Trías, "El instante y las tres eternidades (variaciones sobre temas de Nietzsche)", en Blanca Solares, coord., Los lenguajes del símbolo. Investigaciones de hermenéutica simbólica. Barcelona, Anthropos/UnAM, 2001. 
La noción de límite en su sentido ontológico radical, el ser del límite, la "morada del instante", es el lugar donde, en la filosofía de E. Trías, el ser se recrea a través del principio de variación, una interpretación de la idea del "eterno retorno" de Nietzsche, el origen no dispuesto, la variación no conocida, la recreación eterna de la existencia. Tarea de la filosofía es exponer el trazado categorial del movimiento que somos: una recreación o variación insistente y persistente de ese único tema que constituye nuestra experiencia a cada instante, el pasado inmemorial, el presente eterno y el futuro escatológico. "No hay filosofía sin estilo, escritura y creación literaria”. Sin embargo, tampoco la hay "sin gestación de tramas y urdimbres conceptuales", capaces de permear la experiencia y el registro de los latidos de la vida y hasta la generación de una profunda emoción estética y pasional.

La filosofía es "literatura orientada al conocimiento que además se convalida con la forja de conceptos, y por tanto ha de tener un impulso constructivo". Más en el sentido de una arquitectura del siglo xx, que en el de construcción decimonónica de sistema. "Se trata de la configuración de un entramado arquitectónico donde los conceptos han de estar totalmente hilvanados con las propias expresiones lingüísticas. Esto hace que la filosofía que elaboras sea más difícil y, paradójicamente, más asequible”, pues va mostrando sus avances paso a paso, sin dejar realmente despejado un problema. Así, uno tiene la impresión, después de haber terminado la lectura de alguno de sus libros, de que realmente ha entendido algo, de que en su recorrido algo ha aprendido y se ha aclarado, aunque la sensación sólo sea transitoria y vuelva a tener la necesidad de introducirse en lo que sigue.

\section{Filosofía del límite}

Si seguimos la propuesta filosófica de E. Trías descubrimos, de acuerdo a su propio pensamiento arquitectónico y constructivo, un triángulo equilátero: el ángulo superior alude a una propuesta de ser como ser del límite, los otros dos ángulos inferiores refieren uno a su sentido, logos o razón fronteriza; el otro, a lo que está más allá del ser fronterizo y sus recursos de captación racional o conceptual y que, sin embargo, configuran, desde lo irreductible de su repliegue en el misterio, al ser limítrofe en su mismo fundamento, es decir, desde su dimensión simbólica.

Cabe destacar que el reconocimiento de la dimensión del ser como homo simbolicus o religioso, venía siendo ya un tema primordial, sobre todo, en el ámbito de una transversalidad de saberes humanísticos convergentes en un proyecto hermenéutico por el Círculo de Eranos, constituido por las destacadas y polivalentes figuras, entre otras, de C. G. Jung, M. Eliade, H. Corbin, G. 
Dumezil, E. Newmann, G. Durand, etcétera. Si bien, lo propio del discurso de E. Trías es haber introducido, desde la revisión misma del discurso filosófico y su replanteamiento ontológico, la discusión de los aspectos típicamente desplazados por el predominio del racionalismo ilustrado concebido como progresiva desacralización iconoclasta del mundo.

Lo específico de la propuesta filosófica de Eugenio Trías y lo que la diferencia de otras interpretaciones es que esos tres ángulos, que dan forma a su triángulo ontológico, se encuentran íntimamente entrelazados y que si se afecta la interrelación esencial y dinámica que ellos guardan se altera el conjunto de lo que se quiere expresar. Es decir, que al ser del límite le corresponde una razón fronteriza que no puede ser pensada sino en diálogo con la dimensión simbólica del ser. Y que de la misma manera eso que está más allá y excede el ser, está también en condición limítrofe con el logos, a través del cual haya su posible forma de exposición por medio del suplemento simbólico, una exposición "indirecta y analógica" o simbólica, como diría Kant de lo inconmensurable, pues sólo el símbolo, desde la perspectiva misma de Trías, es capaz de decir lo indecible, de acceder a lo inaccesible y dar forma sensible a lo sagrado en las manifestaciones religiosas y artísticas. ${ }^{6}$

Visto de esta manera, la singularidad del pensamiento de E. Trías consiste no sólo en alterar las nociones filosóficas tradicionales relativas al ser, sino en provocar con ello una radical modificación de las interpretaciones filosóficas del mundo al enfrentarlas continuamente a dialogar con sus sombras, esas huellas o cercos de oscuridad que deja la figura de la luz: las sombras de la sinrazón, el pensamiento mágico, el mundo de las pasiones, la estética de lo siniestro o el pensamiento religioso. A la concepción dominante de razón, hoy en día, como "razón comunicativa", "razón analítica", "razón dialéctica", "racionalidad de acuerdo a fines" o "razón instrumental", enfrenta una noción de razón fronteriza en límite con la condición simbólica de la existencia; a los pensamientos fundados en la doxa del misterio impenetrable derivado en dogmas de fundamentalismos de todo tipo, enfrenta la rigurosa comprensión de un suplemento simbólico, campo y horizonte que se asume en frontera con la razón. A las nociones del ser como "diferencia" o a las diferencias entre ser y ente (Heidegger), así como a toda visión reductiva del ser como zoon economicus, enfrenta una noción del ser como ser del límite. ${ }^{7}$

En su conjunto, esta concepción del ser como ser del límite en constelación triangular con las "dos estrellas binarias" que giran en torno a él, la razón fronteriza y el suplemento simbólico, definiendo y determinando su campo

\footnotetext{
${ }^{6}$ Véase E. Trías, La edad del espíritu, primera parte.

${ }^{7}$ Véase E. Trías, Lógica del limite.
} 
gravitatorio, plantea una verdadera lectura crítica al conjunto de la reflexión filosófica actual y nos arroja a la tarea de volver a revisar hábitos de pensamiento y raciocinio que parecían configurar mundos de vida encerrados en sí, unilateral e inalterablemente, tales como los que privan en las concepciones científicas o las propuestas de corte empírico en los estudios del hombre, que a menudo lo reducen a un manojo de condicionantes causales enfocadas sectorialmente.

La topología del ser del límite, podría quedar brevemente expuesta de la siguiente manera:

- Cerco hermético que alude al más allá, el mundo de los muertos, de los no nacidos aún y de los dioses, resguardado en el misterio insondable;

- cerco del aparecer o despliegue de los mundos de vida realizándose por la acción y el conocimiento del habitante fronterizo, hábitat y cosmos de la humana conditio;

- y cerco fronterizo, justamente, el espacio limítrofe donde se destaca la conjunción y disyunción, las claves hermenéuticas o las verdades y potencias que presiden la unidad ontológica y existencial entre ambos cercos: el cerco del misterio y el cerco de lo que aparece, doble presión que envuelve y acosa la aventura humana.

Y aquí sí, en un mundo como el nuestro, configurado y puesto en marcha como predominio de la razón científico-técnica, el "descubrimiento" de una razón con alcances fronterizos, provoca un auténtico revolutum no sólo en el campo de la reflexión filosófica, sino en el conjunto de los campos del conocimiento humano. Pues si bien, la razón fronteriza puede trazarse su propio recorrido epistemológico tal y como lo muestra E. Trías en su libro $L a$ razón fronteriza, lo peculiar de ella es "disponer de un privilegiado acceso a lo inaccesible (bien que indirecto y analógico) a través de la provisión simbólica", misma que pone al alcance del conocimiento.

De hecho, nos señala E. Trías, es necesario advertir que esas dos estrellas binarias que circulan alrededor del ser del límite permiten cada una de ellas un doble y diferenciado recorrido, en total cuatro, que despliega la topología del triple cerco del ser del límite al que hicimos referencia:

El suplemento simbólico abre el recorrido

1. A la comprensión y experiencia de las formas simbólico religiosas como puente con lo innombrable y absoluto (cerco hermético);

2. tanto como a las configuraciones y elaboraciones artísticas que dan corporalidad al misterio, haciéndolas aparecer en el mundo. 
Arte y religión son, pues, los dos caminos de acceso privilegiado que abre el simbolismo a la comprensión de la realidad humana, a sus relatos míticos, ritos, sacrificios y expresiones estéticas, como dispositivos y acontecimientos de la cita del hombre con lo sagrado. Lógica del límite (1991) y La edad del espíritu (1994) son las dos obras del autor dedicadas al desarrollo de estos aspectos de la experiencia del arte y de la religión en la historia de la humanidad.

La razón fronteriza, de la misma manera, invita al recorrido de una doble ruta

3. Una estrictamente gnoseológica de conocimiento de los distintos trazos y categorías en torno al ser del límite;

4. y otra que indica su uso práctico, la vía de una posible ética del límite, basada en la categoría de libertad, tanto a nivel de la persona como de un ethos o concepción cívico-política, dimanada de la inspiración limítrofe del ser.

El primero de estos aspectos se desarrolla en La razón fronteriza (1999) y el segundo en Ética y condición humana (2000).

Cada una de estas cuatro rutas (religiosa, estética, cognoscitiva y ética) aluden al mismo dato originario de una filosofía del límite. En cada uno de estos trazados, a la vez que se advierte su diferencia, se señala su hermandad. Cada uno de ellos guarda uno de los cuatro barrios trazados por la cruz, horus y staurus, o encrucijada del axis mundi, que ordena el cosmos o la fundación de la Ciudad del límite. El ser del límite puede trazar recorridos de avenidas dobles y entrecruzadas a través de los cuatro barrios de su ciudad: el religioso, el estético, el gnoseológico y el ético.

A la manera de los rituales fundacionales de la ciudad antigua, el augur que atisba en el cielo para trazar a partir de él, sobre la tierra, ejes maestros que guiarán la erección de su ciudad, es ese cruzado, trazado o templo que constituye el ser del límite, el mismo que proyecta sobre la ciudad fronteriza a través de sus cuatro espacios propios y susceptibles de ser habitados: a través de sus modos de producción (poiein), culto religioso, contemplación y conocimiento, o de acción (praxis).

La noción más fecunda de este pensamiento, como ya se advierte desde un principio, se nos regala como límite. Límite, dice E. Trías, espacio de conjunción/disyunción, donde lo que más importa es esa barra o bisagra [ / ] que hace se desborde un cerco y otro en configuraciones lingüísticas. La línea que marca la división entre el mundo, ámbito de lo sensible y lo que está más allá de él, el ámbito indescifrable del misterio o la morada de las madres como advirtiera Mefistófeles al Fausto, de Goethe, es la cuerda floja sobre la que se define nuestro destino. El hombre es el límite del mundo, límite entre 
la vida física y la existencia humana. El límite es el lugar del ser, de la verdad y del sentido. Porque hay límite hay inteligencia o logos, porque hay límite hay razón y porque hay razón hay condición humana.

Límite, dice también E. Trías, topos, espacio que el ser del límite funda a fin de hacerlo habitable -en esto similar al sentido de la expresión romana de los limitanere, los pobladores que viven de los frutos cultivados en el limes, en la franja fronteriza-, a fin de alzar una ciudad donde pueda llegar a ser él mismo, pues el ser en cuanto ser no se da en el mundo sino en el límite entre lo que es y lo que lo trasciende. El límite es, pues, ese espacio donde inteligencia y razón se redefinen a partir de sus propios recursos y dimensiones, donde la inteligencia brota, donde la libertad se decide, donde la pasión se renueva y la muerte y la nada acechan.

La noción de límite tendrá por todo esto un valor hermenéutico, evocará la idea de linde, borde, muro, pero también de acceso, puente y puerta a lo indeterminado. De lo que se trata es, pues, de abrir la noción de límite a la reflexión de toda la sobreabundancia de su campo semántico.

El mundo moderno, caracterizado por el predominio de una conciencia cínica de carácter realista y positivista que nada quiere saber de referencias utópicas y que se nutre de desconfianzas y resquemores con relación a todo horizonte de sentido, parece estar dominado por una razón logocéntrica cuyo único deseo fuera el disfrute de ciertas cuotas de "bienestar" en el marco de la sociedad y de la cultura existente. La "razón fronteriza" se reduce a razón instrumental y el "suplemento simbólico" a realidad espiritual desvalorizada y camuflada. Sin embargo, no es el "desencanto del mundo", como caracterizara Max Weber a la modernidad, lo que singulariza nuestra época, sino la entronización de una razón parcial y la ocultación del símbolo como producción de sentido.

La instalación cínico hedonista en las comodidades y el cálculo racional sometido a la voluntad de dominio, generan una visión del mundo sin horizontes, ni perspectivas, ni sentido ético ni estético, así como el propósito compulsivo de desacralizar toda realidad espiritual sospechosa y de erigir al sujeto como el centro absoluto de un mundo que se agota en sí mismo. Son los rasgos de nuestra modernidad en crisis. Es frente a esa falta de horizontes de la cultura moderna, incapaz de unificar nuestras demandas terrenales, con el "gran anhelo" que el hombre es, que la filosofía del límite se alza como un homenaje a la vida, a su consistencia enigmática que brota y fluye, a eso que Hölderlin llamaba lo aorgico y que no es sino el ser en el vértigo de la pasión propia del límite. Como en el episodio del volantinero del Zaratustra, de F. Nietzsche, la misma pasión, dice E. Trías, "que acucia y asedia, al que camina con la maroma por la leve cuerda de su existir, avisado del abismo que atraviesa”. 